\title{
TRADUCIENDO A WĀSĪNI AL-A'RAŶ: UN ESTUDIO MITOCRÍTICO DEL DUALISMO LÉXICO EN SU OBRA BAYT AL-ANDALUSI
}

\author{
Antonio Torres Fernández \\ Universidad de Alicante
}

\begin{abstract}
Resumen
Este artículo tiene un doble objetivo. Por un lado, traducir parcialmente el primer capítulo de una obra esencial de la literatura argelina del siglo XX: Bayt al-Andalusī, escrito por Wāsīnī al-A'raŷ. Por otro lado, este trabajo pretende analizar, desde la perspectiva de la mitocrítica, el simbolismo que subyace en el uso del vocabulario dualista del autor argelino.
\end{abstract}

Palabras clave: Novela argelina, hermenéutica, simbolismo, mitocrítica, dualismo, Wāsīn̄̄ al-A'raŷ.

\section{INTRODUCCIÓN}

La esencia del simbolismo artístico como herramienta para trasmitir mensajes que trasciendan a la propia obra ha sido, tradicionalmente, objeto de estudio en materias de carácter más visual, como la pintura o la escultura. A nivel filológico, pese a los diferentes modelos y perspectivas de aproximación al hecho literario que existen, las letras no han sido estudiadas, en tantas ocasiones, desde el prisma de la hermenéutica simbólica.

Pese a todo, como muy acertadamente ilustra Luis Garagalza, esta forma de aproximación a la literatura resulta una herramienta crucial para el estudio crítico de las obras literarias, pues dice:

La hermenéutica es un movimiento filosófico que se centra en el problema de la interpretación. La interpretación ahora se entiende como el modo de ser del ser humano y como el modo de ser de la realidad: si somos capaces de interpretar la realidad es porque la realidad es como un texto o como un lenguaje que pueda ser interpretado. La interpretación y el lenguaje son, por lo tanto, leitmotiv de la hermenéutica. Nuestra contribución tiene como objetivo mostrar la importancia de los símbolos en este contexto ${ }^{1}$.

1 Luis Garagalza, “Tras las huellas de Hermes: la hermenéutica simbólica como contribución a los estudios del imaginario”, Cadernos de Educação, 2014, núm. 48, p. 66. 
Siguiendo esta senda de pensamiento, este trabajo centra su atención en una tarea doble. Por un lado, traducir parcialmente el capítulo primero de una obra imprescindible de las letras argelinas actuales: Bayt al-Andalusī, escrita por Wāsīnī al-A'raŷ o Waciny Laredj. Y por otro lado, este trabajo tiene como objetivo analizar el simbolismo subyacente dentro del marco de la literatura argelina contemporánea desde la perspectiva de la mitocrítica y el simbolismo de los arquetipos, aplicada al uso dual del léxico en la citada obra.

\section{LA RELEVANCIA DE LOS SÍMBOLOS EN LA OBRA LITERARIA}

Las obras de creación no solamente poseen valor literario, lingüístico o fonosimbólico, sino que, además de eso, resulta imposible detraer de la creación su valor intrínseco, la carga simbólica directa o indirecta - incluso a veces inconsciente - que marca la experiencia del creador y del receptor. Pero, ¿por qué es relevante la simbología de una obra literaria a la hora de comprender el mensaje que el autor desea transmitir? ¿De qué elementos se sirve el análisis del simbolismo? Como muy bien especifica Mario Tomé Díez:

La posibilidad de una hermenéutica viene dada por la delimitación y clarificación de dos esferas paralelas: lo que en un principio señalábamos como el mundo del 'logos' y del 'mito', o lo que posteriormente evocaría la presencia de un sentido 'literalı y de un sentido 'alegórico', se podría sinterizar ahora en la actuación de la compresión de la interpretación. Mientras que la 'compresión' se sitúa en el plano epistemológico de la captación de realidades o fenómenos físicos, por vía de la reflexión y del análisis racional; por su parte a 'interpretación' se centra en el plano creativo de las producciones humanas (artísticas, espirituales, mentales), fundamentalmente simbólicas, para llevar a cabo un esclarecimiento de las mismas, no necesariamente por vía racional (inconsciente sugestión, asociación, etc. $)^{2}$.

De este modo, la crítica textual puede comprenderse, ya no desde los planos netamente lingüísticos, sino a través de la hermenéutica simbólica.

En este punto es importante referenciar de nuevo palabras de Garagalza:

2 Mario Tomé Díez, “¿Qué es la mitocrítica?”, Estudios humanísticos. Filología, 1986, núm. 8, p. 134. 
En la hermenéutica el problema de la interpretación comparece en su conexión con el lenguaje y se presenta como un problema universal que afecta a toda nuestra experiencia, a nuestro conocimiento del mundo y a la comprensión de nosotros mismos y del otro [...] Cabría decir que el universo cultural humano es un tejido de palabras, modelos, conceptos, teorías, hipótesis..., es decir, de interpretaciones, que media entre el ser humano y la realidad y en el interior del cual ambos (ser humano y realidad) adquieren configuración y determinación correlativa. Pues bien, la hermenéutica estudia precisamente esa relación interpretativa entre el ser humano y lo real y toma esa relación como punto de partida para hacer un replanteamiento de toda la filosofía ${ }^{3}$.

Así, a través del estudio de la obra desde la perspectiva de la hermenéutica simbólica, es posible aproximarse a la literatura a través del imaginario que el autor crea en la mente del lector:

Puede adivinarse el interés de esta posición para un enfoque de la literatura, ya que si se postula que las imágenes son una revelación de y sobre el inconsciente, el estudio del funcionamiento de lo imaginario va a permitir un enfoque de los textos que no va a consistir ni en el repertorio de los efectos de lo real (el mundo de los fenómenos, en la perspectiva de la filosofía de la referencia o una visión del mundo) ni en la articulación del deseo y el lenguaje ${ }^{4}$.

De esta forma, el cuadro analítico del simbolismo y del mitoanálisis debe estructurarse sobre una dimensión múltiple que ha de estar presente a la hora de analizar una obra literaria desde esta perspectiva de la hermenéutica simbólica. Por definición, el símbolo reviste una estructura de reminiscencia arcaica, se sirve de un sustrato conceptual, ya presente, y conocido por el lector para establecer una metacomunicación que va más allá del mero contenido lingüístico, fonosimbólico o estilístico. La relevancia del símbolo radica en el uso que de él hace el autor para establecer una imaginería que puede abstraerse hasta diferentes niveles de profundidad. En otras palabras:

3 Luis Garagalza, loc. cit., p. 67.

4 Jeant Le Galliot, Psicoanálisis y lenguajes literarios: teoría y práctica, Buenos Aires, Edicial, 2001, p. 199. 
E1 símbolo es el medio por el cual se opera el paso de la vivencia a la palabra y de la palabra al discurso. No solo garantiza la traslación de un estado a otro de profundidad o claridad, sino que, por ser operativo, influye en esta misma traslación ${ }^{5}$.

En un primer nivel de abstracción, puede considerarse que:

El símbolo es el movimiento del sentido primario que nos hace participar del sentido latente y así nos asimila con lo simbolizado sin que podamos dominar intelectualmente la semejanza. En este sentido, el símbolo da, es dador, porque es una intencionalidad primaria que da de manera analógica un sentido secundario ${ }^{6}$.

Sin embargo, se debe tener en mente que la presencia de un símbolo o de una imagen alegórica dentro de la obra literaria general, puede no tener relevancia per se dentro de la cosmología subyacente en las letras. Esto es, el autor puede no haber creado esta simbología con un propósito deliberado. Por lo tanto, para analizar un texto de manera consistente, se debe contrastar más la repetición de símbolos arquetípicos y el contexto donde éstos se dan para poder realizar deducciones generales válidas.

En un nivel de abstracción más profundo, se puede observar como el símbolo puede quedar subsumido en el mito, y todo mito está, a su vez, compuesto por mitemas o subunidades del mito con significado propio. Es este conjunto de elementos mito-simbólicos el que dota de profundidad a la metacomunicación imaginativa de una obra literaria y, por lo tanto, es en este contexto donde se debe aplicar en su totalidad la idea del mitoanálisis como teoría crítica del texto literario. Es decir, el mitoanálisis:

Aspira a desvelar, ya sea en un escritor o en la obra de una época y un medio determinado, los mitos directivos y sus transformaciones significativas. Lo cual permitirá constatar cómo un rasgo de carácter personal en un autor contribuye a la modificación de la 'mitología' reinante o bien acentúa la vigencia de uno u otro mito directivo ${ }^{7}$.

De ahí su relevancia para el estudio del hecho literario.

5 Marie F. Begué, "La Simbólica del Mal de Paul Ricoeur comentada”, Teoliterária, 2012, vol. 2, núm. 3, p. 25.

6 Ibid., p. 26.

7 Mario Tomé Díez, loc. cit., p. 136. 


\section{El simbolismo del léxico duAlista en BAYT AL-ANDALUSİ}

Un vez establecido qué es el símbolo y su papel en la configuración del mito dentro de una obra literaria, la pregunta pertinente sería ¿qué elementos destacables a nivel simbólico pueden detectarse al comienzo de la obra Bayt al-Andalusī de Wāsīnī al-A'raŷ? No hay duda de que se trata de una obra compleja y llena de matices, donde podrían encontrarse elementos susceptibles de ser analizados como relevantes para el estudio simbólico de la obra y para su mitoanálisis. Sin embargo, este trabajo se centra solamente en los elementos recurrentes que poseen un denominador común: la simbología religiosa. Y esto es posible debido a que, desde el mismo comienzo de la novela, es posible observar ciertos marcadores discursivos, donde el acervo cultural y religioso del autor y su forma de comprender el mundo aparecen, a veces de manera directa y en otras ocasiones de forma velada, pero siempre están presentes. De hecho, la extrapolación de la fenomenología religiosa al ámbito literario, es decir, trasladar de una manera tácita a la elaboración literaria los esquemas de pensamiento religioso o espiritual del autor, puede $-\mathrm{y}$, de hecho, lo hace - construir de forma determinante la realidad, el discurrir narrativo y la forma en que se configuran los elementos de carácter espiritual, ciertamente evocadores desde el primer momento, para generar en el lector una serie de imágenes mentales arquetípicas y sibilinas a través de determinados contrastes, como se detalla a continuación.

La frase que abre el capítulo primero de la novela es determinante: "No fue la voz cálida de la llamada a la oración lo que me sacó de la cama aquella noche fría y tranquila, ni el soplo del duro y frio viento invernal que se escapaba de las cumbres de las montañas de Sharia, visibles alli a lo lejos, sino el sonido extraño que escuché proveniente de la puerta del jardín". Aquí es posible observar un patrón que se reproducirá durante todo el desarrollo de la novela: extenso uso de sustantivos y adjetivos y, casi en la totalidad de las ocasiones, contrapuesto entre sí. El dualismo del léxico empleado por al-A'raŷ denota la ambivalencia tanto de los personajes como de la esencia literaria de la obra en general.

Este dualismo léxico, igualmente, viene ligado a elementos religiosos, también muy presentes en la novela. La llamada a la oración es descrita como cálida, y la contrapone al frío viento invernal que viene de las 
montañas. Esta dualidad en la primera escena no es baladí. Como bien expresa Sperber:

Dada una oposición, se encuentran otras que le corresponden. El exceso y la moderación, aun cuando no se trate de cualquier exceso o cualquier moderación, son unas categorías lo bastante generales como para que su oposición se halle realizada en numerosos dominios sin que haya en ello descubrimiento importante. Lo mismo se diga para la mayoría de las oposiciones simbólicas abstractas que se encuentran en la literatura: lo alto y lo bajo, lo frío y lo caliente, lo femenino y lo masculino, la derecha y la izquierda, la naturaleza y la cultura, etc. ${ }^{8}$

Sin embargo, aquí la presencia de esos elementos no es tangencial, sino consustancial. La llamada a la oración representa el mundo ideal iluminado, "cálido" frente al "frío" que es la primera forma en la que el autor describe el mundo real que envuelve a los personajes. Este enfrentamiento entre la voz cálida del ad $a n$ y el frío del viento viene a constituir la cristalización del simbolismo dualista en un mitema que configurará un panorama más amplio dentro del mito general empleado, veladamente, por el autor:

Las distintas variaciones del simbolismo solar son la cristalización de arquetipos de tipo luminoso y ascendente, que se expresan en dualidades antagónicas como 'luz/tinieblas' y 'arriba/abajo'. Todo ello nos conduce por la vía del isomorfismo al esquema de acción que se resume en el verbo 'distinguir' y en el que está implícito ese antagonismo, esa división entre la claridad y la oscuridad, entre la ascensión y el descenso?.

$\mathrm{Y}$ es que este antagonismo dualista se observa en la plenitud descrita más arriba por Tomé Díez cuando al-A'raŷ escribe "me pareció ver cuatro sombras desapareciendo en la penumbra, escurriéndose cuesta abajo por la pendiente que llevaba hacia la carretera numero siete, la principal que iba en dirección al mar [...] Segui a aquellas sombras manteniendo cierta distancia hasta el final de la pendiente, justo antes de que la oscuridad se las tragase por completo". Este fragmente observa la totalidad de la simbología del mitema de los eternos enfrentados. Esto es, el ruido extraño de las sombras -y

8 Dan Sperber, El simbolismo en general, Barcelona, Anthropos, 1988, p. 86.

9 Mario Tomé Díez, loc. cit., p. 145. 
no la voz cálida del muecín - es que lo despiertan, y éstas descienden hacia la oscuridad que acaba por engullirlas, simbolizando el descenso al inframundo que acaba engullendo metafóricamente a estos entes oscuros; como si el destino final de aquéllos que deciden ser sombra fuera, irremediablemente, ser engullidos por el abismo infernal de la oscuridad total. Sin embargo, el descenso por la pendiente los lleva al mar. Este hecho no es baladí. El agua es un símbolo poderoso y sugestivo en tanto configuración teológica de diferentes espiritualidades, y posee una connotación clave aquí: se trata de un simbolismo inmemorial y ecuménico de purificación ${ }^{\mathrm{Io}}$. Una vez más Wāsīnī al-A'raŷ traslada de forma indirecta la fenomenología religiosa al ámbito literario. El mar y el agua como elementos simbólicos de exoneración y renacimiento evocan la redención de las sombras: por mucho que se caiga en la oscuridad, por mucho que se descienda hasta sentir que la oscuridad te "engulle", siempre hay una forma de mantener la esperanza de alcanzar la calidez de la salvación.

El adan o llamada a la oración es también un elemento central en este simbolismo, no solamente por lo mencionado anteriormente, sino por los sentimientos tan intensos que genera en el personaje: "El feroz frío [...] terminó de despertarme de la cabezada mañanera que solía echarme en la cama [después de rezar al alba la oración del fajar], mirando hacia el techo vacio. Ciertamente, la llamada a la oración del fajar emociona, te hace sentir cosas extrañas muy adentro. Me retrotrae a tiempos pasados que han dejado en mi recuerdos y nostalgia. La llamada a la oración tiene en su voz una melancolia particular, cada vez que la escucho siento como penetra en mi, la siento en mis entrañas; en algunas ocasiones la siento como una calidez deliciosa, y otras veces resulta una luz ardiente... la melancolía rebosa nostalgia y miedo a lo desconocido". El personaje busca en el adan, como alegoría de la religión islámica, el lugar de destino al que encaminarse para desterrar de sí la inquietud, la desesperanza y el vacío que siente al quedarse sobre la cama dormido mirando al techo en estado contemplativo. La religión —o más bien la religiosidad como pulsión psicológica para escapar de una realidad desasosegante - le supone hallarse a sí mismo en un lugar diferente, fuera del "frío" que le rodea.

10 Mircea Eliade, Tratado de historia de las religiones, México, Biblioteca Era, 2007, p. 185. 
La construcción del mundo real en el que se desarrollan los personajes continúa oponiéndose a los sentimientos de bienestar que despertaba la voz de la llamada a la oración en el personaje. En relación al entorno, escribe el autor: "Cuando llegué a la plaza giré a la derecha y caminé junto al muro del parque, aunque de parque no le quedaba más que el nombre. Hace tiempo se extendia hasta el final de la carretera". El personaje no ve la realidad desde un prisma positivo, como sí ocurre al hablar del adan; por el contrario, incluso los referentes potencialmente positivos del ambiente que le rodea - el parque como alegoría de la naturaleza, por ejemplolos deconstruye con respecto a cómo eran hace tiempo para enfatizar su visión negativa de la realidad. Asimismo, se refiere en términos similares durante las subsiguientes descripciones de los aledaños del citado parque: "que, pese al tiempo, aún se mantenian pegados en las ruinosas paredes. Algunos carteles colgaban como arañas; otros, medio arrancados, se mantenían adheridos a las farolas".

En consonancia con esta percepción pesimista de la realidad, las paredes son descritas como ruinosas, simbolizando una realidad que se desmorona, que degenera al igual los carteles que colgaban, como luchando por mantenerse en un medio hostil. No es cosa menor, en términos de análisis del simbolismo, la descripción que hace el autor de los mencionados carteles: "algunos carteles colgaban como arañas". La araña es un animal que evoca multitud de imágenes arquetípicas:

En la araña coinciden tres sentidos simbólicos distintos, que se superponen, confunden o disciernen según los casos, dominando uno de ellos. Son el de la capacidad creadora de la araña, al tejer su tela; el de su agresividad; y el de la propia tela, como red espiral dotada de un centro [...]. La destructividad del insecto no hace sino ratificar ese símbolo de lo fenoménico. Por esta causa puede decir Schneider que las arañan destruyendo y construyendo sin cesar significa la inversión continua a través de la que se mantiene en equilibrio la vida del cosmos; así, pues, el simbolismo la penetra profundamente en la vida humana para significar aquel 'sacrificio continuo', mediante el cual el hombre se transforma sin cesar durante su existencia ${ }^{11}$.

11 Juan Eduardo Cirlot, Diccionario de símbolos, Barcelona, Siruela, 2006, p. 88. 
El autor se sirve de estas simbologías para transmitir el mensaje velado de lucha, de eterno construir y destruir de la sociedad en la que se desarrolla la obra.

En este fragmento se aprecia, también, cómo la línea temporal, que se mantiene generalmente en el momento presente del personaje, deja entrever cierta referencia indirecta a un pasado no especificado anteriormente en la novela, desconocido, donde se atisba que la regla dualista positivo/ negativo se mantiene como un hilo conductor que enhebra presente y pasado en un todo sustantivo: pasado/bien versus presente/mal en consonancia con esa referencia reiterada a la melancolía y a la nostalgia que vive el personaje al escuchar la llamada a la oración. De hecho, puede entenderse este fragmento como una interrupción temporal y del espacio - a través de la retrospección que hace el personaje para comparar la realidad actual del parque con la realidad del mismo hace unos añosdonde el autor deja deliberadamente ciertos indicios que expresan la angustia y el vacío existencial del personaje por un momento histórico que no se le ha introducido aún al lector. Es decir, todo lo que rodea al personaje está incompleto, vacío, como si de forma simbólica viera en el mundo el vacío interior que le perturba. Así se puede interpretar de los hechos relatados por al-A'raŷ cuando escribe: "solía echarme en la cama [...] mirando hacia el techo vacio" y cuando escribe "Todas las carreteras estaban vacias". El personaje parece encontrarse en un vacío continuo.

Las referencias indirectas que sugieren una extrapolación de la fenomenología religiosa al ámbito literario en esta novela no cesan aquí. La forma en la que se introduce a otro de los personajes no es cosa menor: "[Entre los carteles] vi a Muah al-Kartil, a quien sus parientes solian llamar al-Hâŷy. El apelativo familiar del político, hâŷy (o aquel musulmán que ha hecho la peregrinación a La Meca) categoriza al personaje de una manera que hace que aparezcan en la mente del lector de forma automática toda una serie de cualidades aplicables al personaje - por la mera connotación del hâŷy o peregrinación - sin que sea necesario que el autor las explicite. Se configura, por tanto, como un personaje religioso que abogaba por una "solución islámica" —en este caso el autor sí manifiesta de forma inequívoca la religiosidad del personaje - a los problemas que acucian a la gente, aunque posteriormente en la novela el personaje evolu- 
ciona y se aleja de estos ideales de moral religiosa. De nuevo, se reproduce esta visión dual de arquetipo de hombre religioso enfrentado a la realidad decadente derivada de la inacción de éste y de su progresivo alejamiento de la moral religiosa. Esta forma binaria de concebir el mundo es una constante en la novela. La realidad del presente está en decadencia por el abandono de la espiritualidad y el consiguiente auge de los fantasmas de la acción humana. Es llamativo, en este mismo sentido, la referencia simbólico-religiosa de la derecha (como ejemplo del bien, de los bien guiados; enfrentado a la izquierda como el mal, los descarriados) que se produce en el primer capítulo de la novela: "Cuando llegué a la plaza giré a la derecha y caminé junto al muro del parque”. De este modo, el personaje principal se presenta simbólicamente como el bien guiado, como el que, persiguiendo a las sombras, es capaz de seguir el camino recto.

En esencia, la obra recoge a través de representaciones simbólicas diversas - ya desde su primer capítulo - el mito virtualmente omnipresente en el imaginario humano: la eterna lucha del bien (representado por los elementos de carácter religioso o espiritual y un léxico de connotaciones positivas) contra el mal (antepuesto al primero por léxico de connotaciones negativas y siempre como contraparte contextual del desarrollo temporal y del desarrollo de los personajes a lo largo de la obra) en un mundo donde la realidad resulta desalentadora (por la propia naturaleza humana que no es capaz de alcanzar esos valores de sociedad idealizada) frente la continua idealización del mundo presentado por la religión, que resulta un refugio tentador donde aliviar la desesperanza.

Todo lo descrito anteriormente puede verse de manera más clara con la lectura de la siguiente traducción parcial del primer capítulo de la obra.

IV. Traducción parcial del primer capítulo de la obra Bayt AL-ANDALUSİ

\section{Capitulo primero}

Encuentro en el golfo de Gurabá

No fue la voz cálida de la llamada a la oración lo que me sacó de la cama aquella noche fría y tranquila, ni el soplo del duro y frio viento invernal que se escapaba de las cumbres de las montañas de Sharia, visibles alli a lo lejos, 
sino el sonido extraño que escuché proveniente de la puerta del jardin. Sali apresuradamente al patio. Me pareció ver cuatro sombras desapareciendo en la penumbra, escurriéndose cuesta abajo por la pendiente que llevaba hacia la carretera número siete, la principal que iba en dirección al mar. Durante un segundo tuve la sensación de que una de esas figuras me era familiar por su forma de caminar renqueante, pero rápidamente eliminé esa idea de mi cabeza. Aprendi a ser cauteloso hace mucho tiempo. Segui a aquellas sombras manteniendo cierta distancia hasta el final de la pendiente, justo antes de que la oscuridad se las tragase por completo. Escuché el ruido de un coche mezclarse con el rumor de las olas de mar, cada vez más fuertes. Fue entonces cuando me di cuenta de que aquellas figuras no parecian ser ladrones: no se giraron en ningún momento; eso me hizo sospechar, pero tampoco quise atacarles.

El feroz frío que venía del oeste del golfo de Gurabá terminó de despertarme de la cabezada mañanera que solía echarme en la cama (después de rezar al alba la oración del fajar), mirando hacia el techo vacio. Ciertamente, la llamada a la oración del fajar emociona, te hace sentir cosas extrañas muy adentro. Me retrotrae a tiempos pasados que han dejado en mi recuerdos $y$ nostalgia. La llamada a la oración tiene en su voz una melancolia particular, cada vez que la escucho siento como penetra en mi, la siento en mis entrañas; en algunas ocasiones la siento como una calidez deliciosa, y otras veces resulta una luz ardiente... la melancolía rebosa nostalgia y miedo a lo desconocido.

\section{$* * *$}

Todas las carreteras estaban vacias. Cuando llegué a la plaza giré a la derecha y caminé junto al muro del parque, aunque de parque no le quedaba más que el nombre. Hace tiempo se extendia hasta el final de la carretera, pero habian utilizado una gran parte de su extensión para construir varias casas y almacenes a lo largo de estos últimos veinte años. Mientras caminaba, alcé mi cabeza espontáneamente y observé las farolas, que parecian interrumpir mi camino de una manera singular. Entonces, pude ver las caras de los candidatos al Parlamento en los carteles, que, pese al tiempo, aún se mantenían pegados en las ruinosas paredes. Algunos carteles colgaban como arañas; otros, medio arrancados, se mantenian adheridos a las farolas. Entre los carteles vi a Muah al-Kartil, a quien sus parientes solian llamar al-Haŷy. El fotógrafo habia borrado las marcas que la viruela habia dejado en su cara. Al-Haŷy cambió 


\section{Antonio Torres Fernández}

su forma de pensar y pasó de defender soluciones islámicas y el libre comercio, a residir en el puerto de la capital, donde esperaba los cargamentos de acero, de cemento turco y de mármol español que traian las grandes empresas chinas, españolas y japonesas. Gracias a ello, controlaba todo el mercado local de la construcción. En un principio, quiso ayudar a su gente, pero pronto descubrió que las cosas no iban a ser así. Se presentó a las elecciones por la circunscripción de Aljazair al-Usta, región que nunca habia conocido en realidad. Sus amigos gestionaron toda su campaña. Decidieron comprar una limusina negra, seguros de que, a ojos de los demás, poseyendo un coche semejante, pasaria de ser alguien de escasos recursos a convertirse en una persona bendecida, capaz de proveerles de buenas cosas. Ya se sabe, algunos necesitan grandes estimulos para decidirse. Bajó con la limusina a varios barrios deprimidos a pesar de los consejos que le daban sus familiares sobre lo peligroso que podria resultar hacerlo. Pese a ello, estaba decidido y llevó su campaña a un barrio donde los musulmanes más creyentes prepararon todo lo necesario. Su barba era el pasaporte de legitimación ante ellos. Una vez alli se dirigió a los presentes y dijo:

-Estoy aqui por vosotros; no me hace falta nada. Dios me dio los bienes que necesito.

Sus compañeros más leales se aseguraban de que la gente se moviera por dos motivos: el soborno o las quejas. A buen entendedor, pocas palabras bastan.

Giré la rotonda y volvi a mi calle. La oscuridad se lo habia tragado todo, incluso el golfo de Gurabá, que antes relucia bajo la luz del sol y se veía el reflejo de los peces y la sombra de color bronce sobre el horizonte. Muchos sentimientos afloraron de repente. Cuando fui a abrir la puerta ese mismo dia me di cuenta por primera vez en mucho tiempo de que la escritura de la pared, en árabe y con algunas palabras en bebreo, se mantenía clara pese a que muchas manos intentaron borrarla sin éxito. Abri el buzón amarillo que estaba colocado en la entrada. Habia una pequeña caja decorada con unas letras en color rosa. Cogi lo que habia dentro... era una carta. Supe por la cubierta que era del ayuntamiento. La miré durante un tiempo y la abrí. Solo lei la fecha, escrita en grandes letras en cursiva. No babia pasado ni un mes desde la última carta que habia recibido. Tal vez fuese algo importante. Se lo comenté a Salim y me dijo que fuese a ver a su amigo Karimo, era un buen hombre y se le daba bien todo.

Me dispuse a entrar a la casa, meti la llave en la cerradura con dificultad y escuché la voz de Sara, llamándome desde el jardín de mi casa. 
- Tio Murad, perdona por importunarte. He oído unas voces y unos movimientos extraños, como cuando huyen los animales de los perros y los cazadores que los persiguen. Fui a mirar por todos lados corriendo, estaba segura de que algo pasaba.

\section{Conclusiones}

Desde una perspectiva de análisis centrada en la hermenéutica simbólica, la obra mantiene una visión de dualismo religioso desde el mismo comienzo, donde se conservan los elementos espirituales como marcadores denominativos de la evolución de los personajes y como elementos centrales en la locución del narrador. El dualismo está presente a través de simbolismo y mitemas tanto en la descripción física de la realidad, como en el plano emocional y psicológico de los personajes, que se mueven entre el ideal moral y la realidad desesperanzadora. Es en este ambiente donde se presenta la riqueza, la política y las malas artes como opuestos a la rectitud y la moral religiosa; elementos centrales de la obra, donde el autor traslada el binarismo, la lucha maniquea entre el bien y el mal que se aloja en lo más profundo de la psique humana, al entorno literario, gobernado por la perspectiva arabo-islámica del ideal moral. En esencia, se puede concluir que el autor construye a través del simbolismo dualista un imaginario basado en los elementos religiosos que expresan la naturaleza fundamental del mito de la lucha eterna entre el bien y el mal. 
114 Antonio Torres Fernández

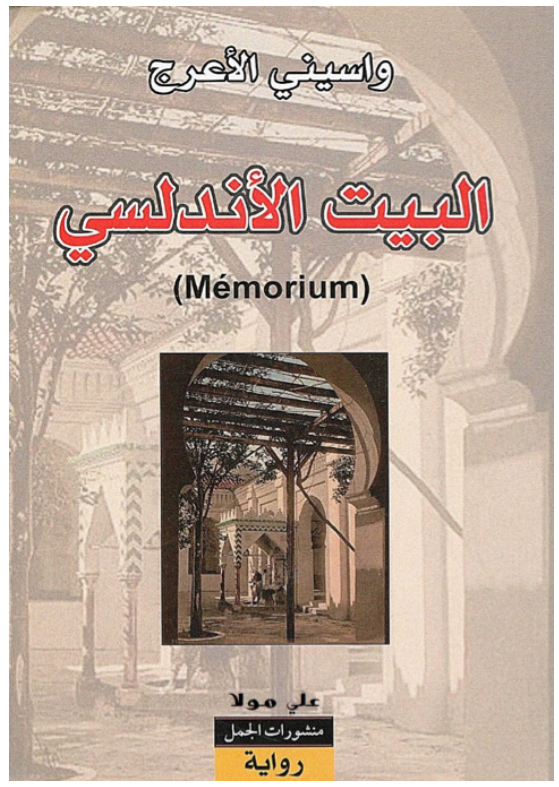

